\title{
Exponential GARCH Model with Exogenous Covariate for South Sudanese Pounds-USD Exchange Rate Volatility: On the Effects of Conflict on Volatility
}

\author{
Abui Peter Kur ${ }^{1}$, Oscar Ngesa², Rachel Sarguta ${ }^{3}$ \\ ${ }^{1}$ Institute for Basic Sciences, Technology and Innovation (PAUSTI), Pan African University, Nairobi, Kenya \\ ${ }^{2}$ Department of Mathematics and Physical Sciences, Taita Taveta University, Voi, Kenya \\ ${ }^{3}$ School of Mathematics, University of Nairobi, Nairobi, Kenya \\ Email: abuipkur@gmail.com, oscanges@ttu.ac.ke, rsarguta@uonbi.ac.ke
}

How to cite this paper: Kur, A.P., Ngesa, O. and Sarguta, R. (2021) Exponential GARCH Model with Exogenous Covariate for South Sudanese Pounds-USD Exchange Rate Volatility: On the Effects of Conflict on Volatility. Journal of Mathematical Finance, 11, 466-483.

https://doi.org/10.4236/imf.2021.113026

Received: June 4, 2021

Accepted: August 10, 2021

Published: August 13, 2021

Copyright $\odot 2021$ by author(s) and Scientific Research Publishing Inc. This work is licensed under the Creative Commons Attribution International License (CC BY 4.0).

http://creativecommons.org/licenses/by/4.0/

\begin{abstract}
The empirical models that explain the variation in exchange rate on the ground of macroeconomic fundamentals only are usually bias on the account of omitted variable hence, they cannot decently explain variations in exchange rate. However, if socio-political determinants, like civil wars, violence are incorporated in simple time series specification, the variations of exchange rate can be understood better. Apparently in developing countries like South Sudan where socio-political problems like conflict are most prevalent, the subject remains largely under-explored. This paper therefore, applies ARMA $(p, q)$ EGARCH $(p, q)$ model with exogenous covariate for SSP-USD exchange rate volatility to examine the effect of conflict as an exogenous variable on exchange rate volatility. The proposed model is $\operatorname{ARMA}(1,2)$-EGARCH $(1,1)$ class of models with exogenous covariate in both mean and volatility equations. An empirical application of the proposed model is demonstrated by incorporating the conflict index as covariate in both mean and volatility equations of the proposed model. Parameter estimation was performed using maximum likelihood estimation method. The estimation results with classical maximum likelihood estimation method suggested that exchange rate volatility was persistent as evidenced by higher values of the coefficient of the parameter that accounts for persistence $(\beta)$ in conditional volatility. Furthermore, the parameter for leverage effect in our models was found to be significant. The results showed that the effects of conflict on volatility of SSP-USD was found positive and statistically significant in both equations indicating that higher prevalence of conflict makes the exchange rate to be more volatile.
\end{abstract}


Keywords

ARMA-EGARCH Model, Covariate, Exchange Rate, Volatility, Maximum Likelihood Estimation, Conflict Index

\section{Introduction}

Exchange rate refers to the number of units of one nation's currency that equals one unit of another country [1]. In the last few decades, the fluctuations and patterns of exchange rate had been a main emphasis of macroeconomic analysis and had drawn the attention of the academicians, financial specialists, and decision makers specifically after failure of agreement on fixed exchange rates amid the industrialized nations referred to as the Bretton Woods agreement. From that time forward, a huge deliberation on the volatility of exchange rate and its possible impact on well-being, inflation, international trade, investment analysis, profitability and risk management have been in the forefront of the debate. As a result, quite good number of models in the finance literature has come into existence for the purpose of probing the exchange rate volatility across distinct parts of the globe and nations. Several models such as the Autoregressive Conditionally Heteroscedastic (ARCH) model and its modifications like the Generalized ARCH (GARCH), Exponential GARCH (EGARCH) and Glosten, Jajanthen and Runkle GARCH (GJR-GARCH) models had been developed to model varying volatility of such series.

ARCH model was proposed by [2]. It clearly tells that the series under consideration has a time-varying variance that rely on the effect of the lags. The ARCH model is approximated upon taking the squared errors and then letting the errors depend on the lags [3]. However, ARCH models are quite often difficult to estimate because they might predict negative volatility as a result of violating non-negativity constraints. Later [4] modified ARCH model into generalized form known as GARCH. The dissimilarity being that the GARCH model permits the conditional variance to rely on its own past values of the squared errors and on the past conditional variance [3]. The GARCH model is parsimonious making it not so much likely to defy non-negativity constraints [5].

Both ARCH and GARCH models of [2] and [4] treat positive shocks and negative shocks symmetrically. That is, their impact on asset volatility is the same. Thus, [6] proposed a GARCH model named EGARCH that allows for asymmetric effects and therefore solved one of the important shortcomings of the symmetric model. While the GARCH model imposes the non-negativity constraint on the parameters, EGARCH uses the log of the conditional variance. Hence, EGARCH is not exposed to the non-negativity constraints [6]. Further advancement to incorporate asymmetric effects was done by [7]. Hence, arriving at a model called GJR-GARCH. It has a merit of modeling the variance directly that is to say, the model does not use the natural logarithm unlike the EGARCH model. Thus, the GJR-GARCH is straightforward to execute [8]. 
The advancements put forward in all those models is achieved by modifying the equation proposed for modeling the conditional volatility, but retaining the same variables.

Standard GARCH models, according to [9], are not well adapted for periods characterized by rapid volatility variations. These factors prompted the improvement of GARCH models. Because the GARCH model is insufficient for forecasting time series impacted by exogenous causes. The ability to uncover underlying patterns in time-series data and quantify the impact of external influences is possible with a time series model incorporating exogenous variables.

Time series analysis with explanatory variables encompasses methods to model and predict correlated data taking into account additional information [10]. External variables' effects on conditional variance can be taken into account using the GARCH-X model. This additional feature becomes even more significant for improving GARCH model predictions, especially when additional factors that can affect GARCH estimates are unaccounted for. GARCH models may generate biased estimates of persistence in variance if these external data are not taken into account.

Several researchers have noted the usefulness of GARCH models with introduction of various exogenous variables for example, [11] used interest rate level, daily market arrivals and interest rate spreads were used as covariates respectively by [12] and [13], a proxy for global information was used as a covariate by [14], volume of traded stock was used by [15] [16] improved GARCH model by bringing in stock's volume as a covariate in volatility equation. [17] explicitly incorporated Acquired immunodeficiency syndrome (AIDS)-associated information to exchange rate of Rand against United State dollar in South Africa.

[18] looked at the volatility of the domestic edible oil price index in India, as well as the effects of exogenous variables such as the international edible oil price index and the Indian-US foreign exchange rate. They discovered that external variables impact the volatility of the domestic price index of edible oil more than its own variance.

Each of the above empirical studies displays a certain improvement of the models by including the exogenous process, and this improvement is presented through computational results obtained on real data. Past studies display that these exogenous factors have a large impact on the study variables and should be included in the existing time series model to improve model performance and forecasting accuracy [19].

[20] investigated GARCH-X by introducing external regressors as proxies for macroeconomic variables of interest, which were tested independently on the mean and variance equations of GARCH-X. However, both the mean and variance equations can be jointly affected by external variables. The effect of covariates was allowed in both equations at the same time in this investigation.

The empirical models that explain the variation in exchange rate on the ground of macroeconomic fundamentals only are usually bias on the account of omitted 
variable hence, they cannot decently explain variations in exchange rate [21]. However, If socio-political determinants, like civil wars, violence are incorporated in simple time series specification, the variations of exchange rate can be understood better [22].

The connection of economic performance and civil war as of late has dominated economic discussion [23]. However, this relationship has been examined in the direction of economic causes and the consequences of civil war by many researchers like [24] and [25]

South Sudan in particular as the country under study has been one of the world's most vulnerable and war-prone nation, unable to break the cycles of conflict since her independence from Sudan in 2011. This cycle of conflict led to economic instability. Therefore, in regard to South Sudan the effect of these socio-political problems mainly conflict on the exchange rate volatility remains largely under-explored. As a result, this paper aims at narrowing down the analysis of the effect of conflict on the dynamics of exchange rate on the basis of quantifying this impact through incorporating conflict index as an exogenous variable to the exponential GARCH model for South Sudanese pounds against united states dollar exchange rate.

The rest of the paper is structured as follows: In Section 2, we presents the methodology and describes the data used. Section 3 gives the exploratory data analysis. Section 4 presents the estimation of mean and volatility equations and the estimation results. Finally, Section 5 gives the conclusion and suggested areas for further research.

\section{Methodology and Data}

Experimental researchers and practicians frequently incorporates covariates to the parameters of volatility dynamic for better modeling and forecasting of volatility in both economic and financial time series particularly to determine whether the inclusion of covarites in $\operatorname{GARCH}(p, q)$, EGARCH $(p, q)$, etc models give an explanation of changes in volatility. As already mentioned by [2], any variance function can be augmented with exogenous variable.

GARCH extended models as put forward by [26] and [27] directly include covariate in conditional variance equation of suggested model. But the exogenous variable can affect the mean and variance equations collectively. Thus we have to test the effect of the covariate in both equations.

In this paper we examined the effect of conflict used as an exogenous variable on exchange rate volatility. The conflict index was treated as counts and dummies. The data used in the empirical application of the proposed model is the daily closing prices of SSP-USD exchange rate and conflict data for the period January 2013 to April 2020.

Each of the data set consists of 2677 observations. The exchange rate data were obtained from central bank of South Sudan officially known as the Bank of South Sudan (BOSS).

The conflict data comes from the Armed Conflict Location and Event Data set 
(ACLED), which covers Africa, the Middle East, and Southeast Asia since 1997 and is disaggregated by date, location, participants, and form of conflict operation [28].

The conflict data mentioned above covers the real-time conflict data in South Sudan on political violence and violence against civilians by the armed groups. The ACLED data can be access through the following link: www.acleddata.com

After obtaining optimal ARMA $(p, q)$-EGARCH $(p, q)$ model, we introduced exogenous variable, the conflict index in both mean and volatility equations of the model. Two forms of conflict index were computed and tested namely, the counts of the conflict and the dummies of the conflict for the entire country and Juba town separately. The counts of conflict index denotes the summation of the number of conflicts observed in a given day for the entire country and Juba separately.

Also, the dummies (one and zero) of the conflict index were considered where one denotes that the conflict was observed in a given day and zero denotes that conflict was not observed in a given day for the whole country and Juba separately. The conflict index treated as the counts for the entire country, counts for Juba town, dummies for the entire country and dummies for Juba town were used as exogenous variables in both mean and volatility equations of the optimal $\operatorname{ARMA}(p, q)$-EGARCH $(p, q)$ model with each treatment of the conflict index entering the model one by one, thus arriving at $\operatorname{ARMA}(p, q)$-EGARCH $(p, q)$ class of models with exogenous variable as follows:

$$
r_{t}=\mu_{t}+a_{t}
$$

$r_{t}$ represent log returns of exchange rates and it follows a simple time series model such as a stationary $\operatorname{ARMA}(p, q), \mu_{t}$ is the mean of the returns, $a_{t}$ refers to the shock which follows a white noise series and is specified as $a_{t}=\sigma_{t} \varepsilon_{t}$. We assumed that $\varepsilon_{t}$ is a sequence of independent and identically distributed random variable with mean of zero and variance 1 .

Model 1

mean equation

$$
r_{t}=\mu+\sum_{i=1}^{p} \phi_{i} r_{t-i}+a_{t}+\sum_{j=1}^{q} \theta_{j} a_{t-j}+\sum_{u=1}^{v} \pi_{u} w_{t-u}
$$

where $\mu$ denotes the mean.

$a_{t}$ denotes shock which follows white noise series.

$\phi$ represents autoregressive coefficient.

$\theta$ represents moving average coefficient.

$\pi_{u}$ represents the coefficient for the exogenous variable.

volatility equation

$$
\log \left(\sigma_{t}^{2}\right)=\omega+\sum_{i=1}^{p} \alpha_{i}\left|\frac{\mu_{t-i}}{\sqrt{\sigma_{t-i}}}\right|+\sum_{j=1}^{q} \beta_{j} \log \left(\sigma_{t-j}^{2}\right)+\sum_{k=1}^{r} \gamma_{k} \frac{\mu_{t-k}}{\sqrt{\sigma_{t-k}}}+\sum_{u=1}^{v} \pi_{u} w_{t-u}
$$

where $\omega$ is the constant term.

$\alpha$ parameter represents a magnitude effect or the symmetric effect of the 
model.

$\beta$ measures the persistence in conditional volatility.

$\gamma$ parameter measures the asymmetric or the leverage effect. $\pi_{u}$ is defined as above.

$w_{t-u}$ is a vector with lagged exogenous variable, the counts of conflict index for the whole country.

Model 2

mean equation

$$
r_{t}=\mu+\sum_{i=1}^{p} \phi_{i} r_{t-i}+a_{t}+\sum_{j=1}^{q} \theta_{j} a_{t-j}+\sum_{u=1}^{v} \pi_{u} x_{t-u}
$$

Volatility Equation

$$
\log \left(\sigma_{t}^{2}\right)=\omega+\sum_{i=1}^{p} \alpha_{i}\left|\frac{\mu_{t-i}}{\sqrt{\sigma_{t-i}}}\right|+\sum_{j=1}^{q} \beta_{j} \log \left(\sigma_{t-j}^{2}\right)+\sum_{k=1}^{r} \gamma_{k} \frac{\mu_{t-k}}{\sqrt{\sigma_{t-k}}}+\sum_{u=1}^{v} \pi_{u} x_{t-u}
$$

where $x_{t-u}$ is a vector with lagged exogenous variable, the dummies of conflict index for the whole country.

Model 3

mean equation

$$
r_{t}=\mu+\sum_{i=1}^{p} \phi_{i} r_{t-i}+a_{t}+\sum_{j=1}^{q} \theta_{j} a_{t-j}+\sum_{u=1}^{v} \pi_{u} y_{t-u}
$$

Volatility Equation

$$
\log \left(\sigma_{t}^{2}\right)=\omega+\sum_{i=1}^{p} \alpha_{i}\left|\frac{\mu_{t-i}}{\sqrt{\sigma_{t-i}}}\right|+\sum_{j=1}^{q} \beta_{j} \log \left(\sigma_{t-j}^{2}\right)+\sum_{k=1}^{r} \gamma_{k} \frac{\mu_{t-k}}{\sqrt{\sigma_{t-k}}}+\sum_{u=1}^{v} \pi_{u} y_{t-u}
$$

where $y_{t-u}$ is a vector with lagged exogenous variable, the counts of conflict index for Juba.

Model 4

mean equation

$$
r_{t}=\mu+\sum_{i=1}^{p} \phi_{i} r_{t-i}+a_{t}+\sum_{j=1}^{q} \theta_{j} a_{t-j}+\sum_{u=1}^{v} \pi_{u} z_{t-u}
$$

Volatility Equation

$$
\log \left(\sigma_{t}^{2}\right)=\omega+\sum_{i=1}^{p} \alpha_{i}\left|\frac{\mu_{t-i}}{\sqrt{\sigma_{t-i}}}\right|+\sum_{j=1}^{q} \beta_{j} \log \left(\sigma_{t-j}^{2}\right)+\sum_{k=1}^{r} \gamma_{k} \frac{\mu_{t-k}}{\sqrt{\sigma_{t-k}}}+\sum_{u=1}^{v} \pi_{u} z_{t-u}
$$

where $z_{t-u}$ is a vector with lagged exogenous variable, the dummies of conflict index for Juba.

If $\pi=0$, the coefficient of the vector with lagged exogenous variable then the models reduces to ARMA $(p, q)$-EGARCH $(p, q)$ without exogenous variable.

\section{Exploratory Data Analysis}

The daily SSP-USD currency exchange rate was first subjected to a stationarity test. An Augmented Dickey-Fuller test (ADF) for a unit root in a time series 
sample was used to check for stationarity. The null hypothesis of the test is that there is a unit root. The p-value obtained should be smaller than the significance level (say 0.05) in order to reject the null hypothesis of the test. The test results are given in Table 1.

There is no reason to reject the null hypothesis because the $\mathrm{p}$-value is greater than the significance level of 0.05 . As a result, the series is not stationary. Hence, the series must be difference in order to become stationary.

The exchange rate data is then transformed into daily log returns using the following returns formula.

$$
r_{t}=\ln \left(\frac{p_{t}}{p_{t-1}}\right)
$$

where,

$r_{t}$ is the log return of the exchange rate.

$p_{t}$ is the exchange rate at time $t$

$p_{t-1}$ is the exchange rate at time $t-1$

The Augmented Dickey-Fuller test results after the series was transformed into daily log returns confirm that the series is stationary as can be seen in Table 2.

The p-value is less than the significance level and hence we can reject the null hypothesis and take that the series is stationary.

\subsection{Descriptive Statistics for Exchange Rates and Conflict Data}

In Table 3, the statistics shown under SSP-USD exchange rate prices indicates that mean is 119.845 , maximum of 333.330 , minimum of 3.850 , the interquartile range is 238.000 . The statistics shown under SSP-USD exchange rate returns gives the mean for the returns as 0.002 and kurtosis is 37.419 which is larger than 3, hence leptokurtic when compared to normal distribution. The basic statistics of ACLED for whole Country as shown above indicates that the mean is 2.172 with zero as minimum, maximum of 10.000 , median of 2.000 and the interquartile range is 2.000. The basic statistics of ACLED data set for Juba indicates that the mean is 0.873 with zero as minimum, maximum of 6.000 , median of 1.000 and the interquartile range is 1.000 .

\subsection{Time Series Plot of Exchange Rate Prices}

As shown in Figure 1, the SSP have a fair stability between the year 2013 and 2015. Due to the intensification of the war in the country there was a diminution of SSP against USD. This decline continued upto mid 2016 then followed by a relative calm in the beginning of the second half of 2016 when the agreement on the resolution on the conflict in South Sudan was signed following the cease fire agreement and the subsequent formation of the government of national unity. However, the outbreak of the war again in July 2016 accounts for the rapid decline in the value of SSP but upon the signing of the revitalized agreement on the resolution of conflict after cease fire agreement in 2018, little calm in the value of 
SSP was noticed but due to limited supply of USD as a result of dropped in the oil prices in the international market, SSP kept declining for the whole of the year 2019 and beginning of the year 2020 but the formation of the revitalize government of national unity in early 2020 accounts for the little calm which did not last for long.

Table 1. Augmented dickey-fuller test.

\begin{tabular}{cc}
\hline & Value \\
\hline ADF statistic & -2.2 \\
Lag order & 13 \\
P-value & 0.494 \\
\hline
\end{tabular}

Table 2. Augmented Dickey-Fuller test for log returns.

\begin{tabular}{cc}
\hline & Value \\
\hline ADF statistic & -14.54 \\
Lag order & 13 \\
P-value & 0.01 \\
\hline
\end{tabular}

Table 3. Descriptive Statistics.

\begin{tabular}{ccccc}
\hline Statistic & SSP-USD Prices & SSP-USD Returns & Whole Country & Juba \\
\hline Minimum & 3.850 & -0.259 & 0.000 & 0.000 \\
$1^{\text {st }}$ Quartile & 5.400 & 0.000 & 1.000 & 0.000 \\
Median & 73.500 & 0.000 & 2.000 & 1.000 \\
Mean & 119.845 & 0.002 & 2.172 & 0.873 \\
$3^{\text {rd }}$ Quartile & 244.000 & 0.005 & 3.000 & 1.000 \\
Maximum & 333.330 & 0.268 & 10.000 & 6.000 \\
Kurtosis & -1.428 & 37.419 & -0.012 & 1.515
\end{tabular}

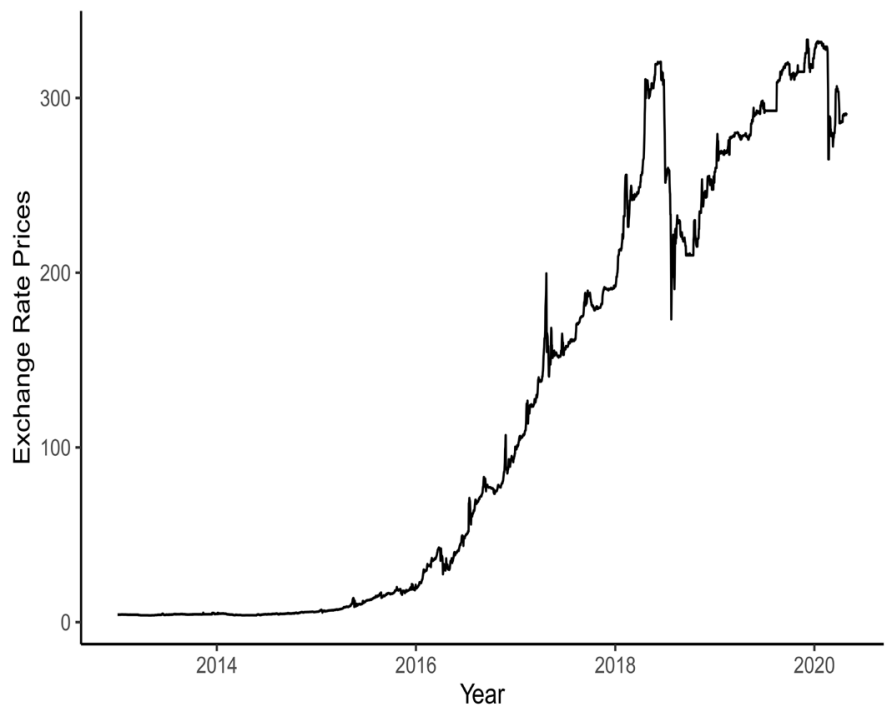

Figure 1. Exchange rate for SSP-USD for the period of January 1, 2013 to April 30, 2020. 


\subsection{Time Series Plot of Log Returns for Exchange Rate}

The merit of converting the exchange rate returns into their logarithmic equivalent is that the statistical properties of the logarithmic returns can easily be obtained.

From the plot of log returns in Figure 2, it can be easily observed that small changes are followed by further small changes and large changes followed by further large changes, thus volatility clustering was observed. Also, the mean reverting characteristic where returns tend to remain around a certain value can also be seen clearly.

\section{Estimation of Mean and Volatility Equations}

\subsection{Estimation of Mean Equation}

An ARMA $(p, q)$ model was used to fit the mean returns. To evaluate the order of ARMA $(p, q)$ models, the Autocorrelation Function (ACF) and Partial Autocorrelation Function (PACF) are used. The optimal ARMA model for SSP-USD exchange rate was determined using the AIC, BIC and Log likelihood criterion. In Table 4 , the optimal model for the SSP-USD is the ARMA $(1,2)$ since it has the lowest BIC value which often gives penalty for the additional parameters.

\subsection{Testing for ARCH Effects}

We must first guarantee that the data is volatile before fitting the EGARCH model. The Box-Ljung test is used to test for the existence of ARCH effects using the squared residuals from the fitted mean equation in Table 4. The test's null hypothesis is that there are no ARCH effects, while the alternative hypothesis is that there are ARCH effects. Since the p-value is less than 0.05, ARCH effects are present in the SSP-USD Exchange rate. Thus we reject the null hypothesis and conclude that there are ARCH effects as indicated in Table 5.

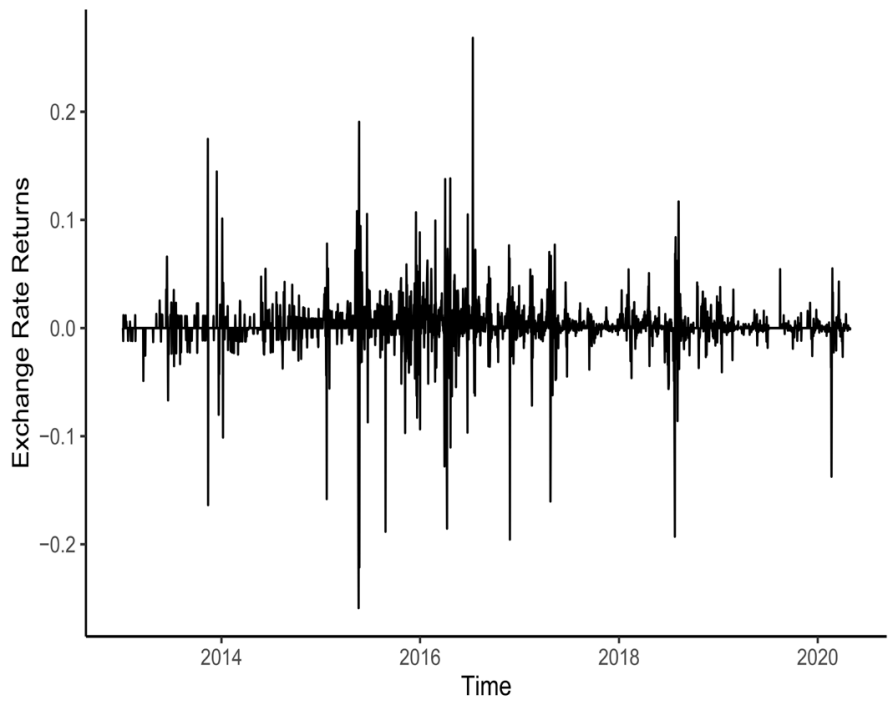

Figure 2. Log Returns of SSP-USD Exchange rate for the period of January 1, 2013 to April 30, 2020. 
Table 4. Criterion for ARMA $(p, q)$ Selection for SSP-USD Exchange Rate.

\begin{tabular}{cccc}
\hline Model & Log Likelihood & AIC & BIC \\
\hline ARMA $(1,1)$ & 6370.56 & $-12,733.13$ & $-12,709.56$ \\
ARMA $(1,2)$ & 6382.45 & $-12,754.91$ & $-12,725.44$ \\
ARMA $(2,1)$ & 6381.88 & $-12,753.77$ & $-12,724.31$ \\
ARMA $(2,2)$ & 6382.65 & $-12,753.29$ & $-12,717.94$ \\
\hline
\end{tabular}

Table 5. Box-Lyung test for ARCH effects.

\begin{tabular}{ccc}
\hline Exchange Rate & Chi-Square Value & p-Value \\
\hline SSP-USD & 31.8960 & $1.627 \mathrm{e}^{-08}$ \\
\hline
\end{tabular}

\subsection{Estimation of Volatility Equation}

EGARCH $(p, q)$ model was used to fit volatility equation. The optimal EGARCH model for SSP-USD exchange rate was determined using the AIC, BIC and Log likelihood criterion. In the Table below, the optimal model for the SSP-USD is the EGARCH $(1,1)$ since it has the lowest BIC value which often gives penalty for the additional parameters (Table 6).

\subsection{Estimation Results}

As a starting point, we estimated the ARMA $(1,2)$-EGARCH $(1,1)$ under the assumption that the innovations are students'-t distributed for SSP-USD for the period 2013-2020. Parameter estimates of model with Maximum Likelihood estimator are given in Table 7.

Mean equation of model without exogenous variable

$$
r_{t}=\mu+\phi_{1} r_{t-1}+a_{t}+\theta_{1} a_{t-1}+\theta_{2} a_{t-2}
$$

where $\mu$ denotes the mean.

$a_{t}$ denotes shock which follows white noise series.

$\phi$ represents autoregressive coefficient.

$\theta$ represents moving average coefficient.

Volatility equation of model without exogenous variable

$$
\log \left(\sigma_{t}^{2}\right)=\omega+\alpha_{1}\left|\frac{\mu_{t-1}}{\sqrt{\sigma_{t-1}}}\right|+\beta_{1} \log \left(\sigma_{t-1}^{2}\right)+\gamma_{1} \frac{\mu_{t-1}}{\sqrt{\sigma_{t-1}}}
$$

where $\omega$ is the constant term.

$\alpha$ parameter represents a magnitude effect or the symmetric effect of the model.

$\beta$ measures the persistence in conditional volatility.

$\gamma$ parameter measures the asymmetric or the leverage effect.

The values of the constant terms that is to say $\mu$ and $\omega$ are 0.0002 and -0.2873 respectively. The value of $(\alpha)$, the parameter representing symmetry or magnitude effect of the model is -0.0160 . The value of parameter that measure persistence in conditional volatility, $\beta$ is 0.9676 indicating that volatility last 
Table 6. Criterion for EGARCH ( $p, q)$ Selection for SSP-USD Exchange Rate.

\begin{tabular}{cccc}
\hline Model & Log Likelihood & AIC & BIC \\
\hline EGARCH $(1,1)$ & $\mathbf{8 8 3 9 . 8 4 4}$ & -6.5985 & -6.5743 \\
EGARCH $(1,2)$ & 8832.776 & -6.5940 & -6.5720 \\
EGARCH $(2,1)$ & 8824.421 & -6.5885 & -6.5678 \\
EGARCH $(2,2)$ & 8840.167 & -6.5980 & -6.5716 \\
\hline
\end{tabular}

Table 7. Parameter estimates of model without exogenous covariate.

\begin{tabular}{cccc}
\hline Parameter & Estimate & Std Error & p-Value \\
\hline$\mu$ & 0.0002 & 0.0000 & 0.0000 \\
$\phi$ & 0.9949 & 0.0100 & 0.0000 \\
$\theta_{1}$ & -0.9567 & 0.0001 & 0.0000 \\
$\theta_{2}$ & -0.0349 & 0.0141 & 0.0133 \\
$\omega$ & -0.2873 & 0.0030 & 0.0000 \\
$\alpha_{1}$ & -0.0160 & 0.0724 & 0.8252 \\
$\beta_{1}$ & 0.9676 & 0.0003 & 0.0000 \\
$\gamma_{1}$ & 0.4886 & 0.0708 & 0.0000 \\
\hline
\end{tabular}

longer before dying out following crisis in exchange rate market. Furthermore, the autoregressive term is positive and statistically significant whereas both moving average terms are negative and statistically significant. The coefficient of asymmetry parameter is positive and statistically significant.

When the covariate entered Equations (11) and (12) in additive form, we obtained the ARMA $(1,2)$-EGARCH $(1,1)$ class of models with covariate in the forms of the counts of conflict index for the whole country, dummies of the conflict index for the whole country, counts of the conflict index for Juba town and dummies of conflict index for Juba town as shown in model 1 to model 4 above respectively. The estimation results are shown in the preceding tables.

After including the covariate in both mean and volatility equations as shown in Table 8 and using the Students'-t distribution as the distribution of error, we then compare the results obtained with $\operatorname{EGARCH}(1,1)$ without exogenous covariate.

The autoregressive term $(\phi)$ increased by 0.0005 in absolute and $0.05 \%$ in term of percentage, meanwhile, the first moving average coefficient $\left(\theta_{1}\right)$ decreased by 0.0085 in absolute and $-0.89 \%$ in term of percentage but the second moving average coefficient $\left(\theta_{2}\right)$ increased by 0.0084 in absolute terms.

In mean equation, the particular interest lies in the coefficient for the covariate. The estimation results shows that it is positive and statistically significant at $1 \%, 5 \%$ and $10 \%$ levels of significant. By this result, we can infer that there is significant effect of conflict on SSP-USD exchange rates in mean equation. More so, in the volatility equation after including the covariate, it has been observed that the coefficient for parameter that measures persistence in conditional vola- 
tility $(\beta)$ increased by 0.0089 in absolute terms and $0.92 \%$ in percentage, however, for $\alpha$, the case is different in the sense that the effect is 0.0411 decrease in absolute term.

The parameter for the asymmetry reveals a decrease of 0.1224 in absolute term and in term of percentage, it is $25.05 \%$. However, the main finding which is of special interest is the coefficient for the covariate in Table 8. The results reveals that coefficient for the covariate is positive and statistically significant thus it affects volatility of SSP-USD exchange rates in the sense that any increase in the coefficient of the covariate, the volatility increases and the reverse is true.

After including the covariate in terms of the dummies for the counts of the conflict in the entire Country in both mean and volatility equations as shown in Table 9 and using the Students'-t distribution as the distribution of error, we then compare the results obtained with EGARCH $(1,1)$ without exogenous covariate.

Table 8. Parameter estimates of model with counts of Conflict index for the whole country as exogenous covariate (Model 1).

\begin{tabular}{cccc}
\hline Parameter & Estimate & Std Error & p-Value \\
\hline$\mu$ & -0.0028 & 0.0001 & 0.0014 \\
$\phi$ & 0.9954 & 0.0006 & 0.0000 \\
$\theta_{1}$ & -0.9652 & 0.0000 & 0.0000 \\
$\theta_{2}$ & -0.0265 & 0.0007 & 0.0000 \\
$\pi_{1}$ & 0.0002 & 0.0000 & 0.0000 \\
$\omega$ & -0.3368 & 0.0153 & 0.0000 \\
$\alpha_{1}$ & -0.0571 & 0.0265 & 0.0311 \\
$\beta_{1}$ & 0.9765 & 0.0002 & 0.0000 \\
$\gamma_{1}$ & 0.3662 & 0.0344 & 0.0000 \\
$\pi_{2}$ & 0.0580 & 0.0074 & 0.0000 \\
\hline
\end{tabular}

(phi_1) and (phi_2) denote the coefficients for conflict index in mean and volatility equations respectively.

Table 9. Parameter estimates of model with dummies of Conflict index for the whole country as exogenous covariate (Model 2).

\begin{tabular}{cccc}
\hline Parameter & Estimate & Std Error & p-Value \\
\hline$\mu$ & -0.0003 & 0.0001 & 0.0006 \\
$\phi$ & 0.9952 & 0.0008 & 0.0000 \\
$\theta_{1}$ & -0.9581 & 0.0000 & 0.0000 \\
$\theta_{2}$ & -0.0334 & 0.0010 & 0.0000 \\
$\pi_{1}$ & 0.0005 & 0.0001 & 0.0000 \\
$\omega$ & -0.6523 & 0.0117 & 0.0000 \\
$\alpha_{1}$ & -0.1153 & 0.0379 & 0.0023 \\
$\beta_{1}$ & 0.9531 & 0.0041 & 0.0000 \\
$\gamma_{1}$ & 0.5185 & 0.0572 & 0.0000 \\
$\pi_{2}$ & 0.3049 & 0.0551 & 0.0000 \\
\hline
\end{tabular}


The autoregressive term $(\phi)$ increased by 0.0003 in absolute and $0.03 \%$ in term of percentage, meanwhile, the first moving average coefficient $\left(\theta_{1}\right)$ decreased by 0.0014 in absolute and $-0.15 \%$ in term of percentage but the second moving average coefficient $\left(\theta_{2}\right)$ increased by 0.0015 in absolute terms.

In the mean equation, the particular interest lies in the coefficient for the covariate. The estimation results shows that it is positive and statistically significant at $1 \%, 5 \%$ and $10 \%$ levels of significant. By this result, we can deduce that there is a significant effect of conflict on SSP-USD exchange rates in mean equation. Additionally, in the volatility equation after including the covariate, it has been observed that the coefficient for parameter that measures persistence in conditional volatility $(\beta)$ decreased by 0.0145 in absolute terms and $1.50 \%$ in percentage, but generally, the persistent level is high also, for $\alpha$, the case is similar in the sense that the effect is 0.0993 decrease in absolute term.

The parameter for the asymmetry reveals a increase of 0.0299 in absolute term and in term of percentage, it is $6.12 \%$. However, the major finding which is the focus of our attention is the coefficient for the covariate in Table 9. The results shows that coefficient for covariate is positive and statistically significant therefore, the conditional variance of SSP-USD exchange rate in this regard was significantly affected by the conflict. The effect of the covariate on the volatility is that, it increases the volatility as it increases in magnitude.

After including the covariate in terms of the counts of the conflict index in Juba town in both mean and volatility equations as shown in Table 10 and using the Students'-t distribution as the distribution of error, we then compare the results obtained with EGARCH $(1,1)$ without exogenous covariate.

The autoregressive term $(\phi)$ increased by 0.0006 in absolute and $0.06 \%$ in term of percentage, meanwhile, the first moving average coefficient $\left(\theta_{1}\right)$ decreased by 0.0046 in absolute and $-0.48 \%$ in term of percentage however, the second moving average coefficient $(\theta)$ increased by 0.0044 in absolute terms.

In the mean equation, the particular interest lies in the coefficient for the covariate. The estimation results shows that the covariate was positive and statistically significant at $5 \%$ and $10 \%$ levels of significant. By this result, we can conclude that there is a significant effect of conflict on the SSP-USD exchange rates in mean equation. Also, it had been observed that the coefficient for parameter that measures persistence in conditional volatility $(\beta)$ in the volatility equation increased by 0.0072 in absolute terms and $0.74 \%$ in percentage after including the covariate. Additionally, for $\alpha$, the case is similar in the sense that the effect is $0.68 \%$ increase which equates to 0.0066 increase in absolute term. Hence the persistent level was high generally.

The parameter for the asymmetry reveals a decrease of $21.02 \%$ and 0.1027 in absolute terms. However, the major finding which is the focus of our attention is the coefficient for the covariate in Table 10. The results shows that the coefficient for covariate is positive and statistically significant therefore, the volatility of SSP-USD exchange rates is largely affected by the conflict in the sense 
that, as the conflict escalates, volatility of exchange rates continue to rise and vice versa.

After including the covariate in terms of the dummies of the conflict index in Juba town in both mean and volatility equations as shown in Table 11 and using the Students'-t distribution as the distribution of error, we then compare the results obtained with EGARCH $(1,1)$ without exogenous covariate.

The autoregressive term $(\phi)$ increased by $0.07 \%$ and 0.0007 in absolute. Meanwhile, the first moving average coefficient $\left(\theta_{1}\right)$ decreased by 0.0038 in absolute and $-0.40 \%$ in term of percentage. The case of second moving average coefficient $\left(\theta_{2}\right)$ is different in the sense that it increased by 0.0035 in absolute terms.

Table 10. Parameter estimates of model with counts of Conflict index for Juba as exogenous covariate (Model 3).

\begin{tabular}{cccc}
\hline Parameter & Estimate & Std Error & p-Value \\
\hline$\mu$ & 0.0000 & 0.0001 & 0.7139 \\
$\phi$ & 0.9955 & 0.00134 & 0.0000 \\
$\theta_{1}$ & -0.9613 & 0.0000 & 0.0000 \\
$\theta_{2}$ & -0.0305 & 0.0020 & 0.0000 \\
$\pi_{1}$ & 0.0001 & 0.0001 & 0.0384 \\
$\omega$ & -0.2873 & 0.0091 & 0.0000 \\
$\alpha_{1}$ & -0.0558 & 0.0259 & 0.0311 \\
$\beta_{1}$ & 0.9748 & 0.0002 & 0.0000 \\
$\gamma_{1}$ & 0.3859 & 0.0357 & 0.0000 \\
$\pi_{2}$ & 0.0715 & 0.0119 & 0.0000
\end{tabular}

Table 11. Parameter estimates of model with dummies of Conflict index for Juba as exogenous covariate (Model 4).

\begin{tabular}{cccc}
\hline Parameter & Estimate & Std Error & p-Value \\
\hline$\mu$ & 0.0001 & 0.0000 & 0.0000 \\
$\phi$ & 0.9956 & 0.0011 & 0.0000 \\
$\theta_{1}$ & -0.9605 & 0.0000 & 0.0000 \\
$\theta_{2}$ & -0.0314 & 0.0017 & 0.0000 \\
$\pi_{1}$ & 0.0001 & 0.0001 & 0.0977 \\
$\omega$ & -0.3107 & 0.0147 & 0.0000 \\
$\alpha_{1}$ & -0.0388 & 0.0242 & 0.1091 \\
$\beta_{1}$ & 0.9742 & 0.0002 & 0.0000 \\
$\gamma_{1}$ & 0.3806 & 0.0374 & 0.0000 \\
$\pi_{2}$ & 0.1390 & 0.0270 & 0.0000
\end{tabular}


In the mean equation, the particular interest lies in the coefficient for the covariate. The estimation results demonstrated positivity and significant of covariate at only $10 \%$ level of significant. Based on the above results from the mean equation, we can conclude that there is a significant effect of conflict on SSPUSD exchange rates in mean equation. Also, it has been observed that the coefficient for parameter that measures persistence in conditional volatility $(\beta)$ in the volatility equation increased by 0.0066 in absolute terms and $0.68 \%$ in percentage after including the covariate. Also, for the parameter $\alpha$, the case is quite different as the effect is 0.0228 decrease in absolute term.

The parameter for the asymmetry reveals a decrease of $22.10 \%$ and 0.1080 in absolute terms. However, the major finding which is the focus of our attention is the coefficient for the covariate in Table 11. The results reveals that coefficient for covariate is positive and significant therefore, we deduced that the SSP-USD exchange rate becomes more volatile as the conflict increases.

\subsection{Check for the Adequacy of Fitted Models}

Finally, we used the Ljung-Box Q-test as a post estimation test to test for autocorrelation of the standardized squared residuals of fitted models. The null hypothesis is that the residuals show no autocorrelation, while the alternative is that there is autocorrelation among the residuals. We used the test to see if our models are adequately fitted or not. If they are, there should be no autocorrelation present.

Since all the p-values at the given lags in all the models in Table 12 are greater than the significance level of 0.05 , we fail to reject the null hypothesis and conclude that our models adequately fitted the data.

Table 12. Weighted Ljung-Box test on standardized squared residuals for models.

\begin{tabular}{ccc}
\hline Lag & Statistic & P-value \\
\hline lag (1) & Model 1 & \\
\hline $\operatorname{lag}(5)$ & 0.0355 & 0.8506 \\
lag (9) & 0.1195 & 0.9973 \\
\hline & 0.2377 & 0.9999 \\
\hline $\operatorname{lag}(1)$ & Model 2 & 0.8560 \\
\hline $\operatorname{lag}(5)$ & 0.0330 & 0.9974 \\
$\operatorname{lag}(9)$ & 0.1171 & 0.9999 \\
\hline $\operatorname{lag}(1)$ & 0.2400 & 0.9510 \\
\hline $\operatorname{lag}(5)$ & Model 3 & 0.9991 \\
$\operatorname{lag}(9)$ & 0.0038 & 1.0000 \\
\hline $\operatorname{lag}(1)$ & 0.0264 & 1.0000 \\
\hline $\operatorname{lag}(9)$ & 0.0693 & 0.8813 \\
\hline & Model 4 & 0.9992 \\
\hline
\end{tabular}

(phi_1) and (phi_2) denote the coefficients for conflict index in mean and volatility equations respectively. 


\section{Conclusions and Suggestions}

The prime goal of this paper was to examine the effects of conflict on SSP-USD exchange rates volatility. The methodology follows EGARCH model with exogenous covariate in both mean and volatility equations.

The time series of South Sudanese exchange rate returns had been explored and appropriate $\operatorname{ARMA}(p, q)$-EGARCH $(p, q)$ model was formulated. On the basis of information criteria, the ARMA $(1,2)-\operatorname{EGARCH}(1,1)$ was the optimal volatility model. The ARMA process was used to estimate the mean equation as it acts as filter for the returns in order to produce independent and identically distributed returns.

The empirical application of the proposed model was demonstrated by adding the conflict index in different forms in both mean and volatility equations of the optimal model. Thus, we obtained ARMA $(1,2)$-EGARCH $(1,1)$ class of models with exogenous variable. In this way, we have attempted to capture the effects of covariate on the dynamics of the SSP-USD exchange rates volatility. The estimated results with maximum likelihood estimation for ARMA $(1,2)$-EGARCH $(1,1)$ class of models with exogenous variable shows that the values of the parameter beta $(\beta)$ in all the models were close to one, indicating that volatility in exchange rates was persistent and parameter for leverage effect in our models was significant. The effect of conflict on volatility of SSP-USD was generally positive and statistically significant in both equations indicating that the prevalence of conflict makes the exchange rate to be more volatile. As a result, exchange rate volatility can have an impact on the business and investor sectors because it increases market uncertainty and risk. As a result of the aforementioned risk, foreign direct investors are forced to leave the country in order to protect their businesses.

Therefore, policymakers must be aware of the degree of exchange rate volatility in order to implement appropriate economic policies. As a result, the outcomes are crucial from a policy standpoint.

Further research focusing on exploring non-linear effects of the exogenous variables on the volatility of SSP-USD exchange rate can be undertaken.

Also, there is a room for extending the model assuming the covariate can be modeled as a function of other variables or may have other distribution functions.

\section{Acknowledgements}

The first author thanks the Pan-African University Institute of Basic Sciences, Technology and Innovation (PAUSTI) for their support.

\section{Conflicts of Interest}

The authors declare no conflicts of interest regarding the publication of this paper. 


\section{References}

[1] Tucker, I.B. (2010) Economics for Today. Cengage Learning, Boston.

[2] Engle, R.F. (1982) Autoregressive Conditional Heteroscedasticity with Estimates of the Variance of United Kingdom Inflation. Econometrica: Journal of the Econometric Society, 50, 987-1007. https://doi.org/10.2307/1912773

[3] Brooks, C. (2019) Introductory Econometrics for Finance. Cambridge University Press, Cambridge. https://doi.org/10.1017/9781108524872

[4] Bollerslev, T. (1986) Generalized Autoregressive Conditional Heteroskedasticity. Journal of Econometrics, 31, 307-327. https://doi.org/10.1016/0304-4076(86)90063-1

[5] Campbell, J.Y., Lo, A.W., MacKinlay, A.C. and Whitelaw, R.F. (1998) The Econometrics of Financial Markets. Macroeconomic Dynamics, 2, 559-562. https://doi.org/10.1017/S1365100598009092

[6] Nelson, D.B. (1991) Conditional Heteroskedasticity in Asset Returns: A New Approach. Econometrica: Journal of the Econometric Society, 59, 347-370. https://doi.org/10.2307/2938260

[7] Glosten, L.R., Jagannathan, R. and Runkle, D.E. (1993) On the Relation between the Expected Value and the Volatility of the Nominal Excess Return on Stocks. The Journal of Finance, 48, 1779-1801. https://doi.org/10.1111/j.1540-6261.1993.tb05128.x

[8] Hayashi, F. (2000) Single-Equation GMM. Econometrics, New Jersey.

[9] Andersen, T.G., Bollerslev, T., Diebold, F.X. and Labys, P. (2003) Modeling and Forecasting Realized Volatility. Econometrica, 71, 579-625. https://doi.org/10.1111/1468-0262.00418

[10] Maçaira, P.M., Thomé, A.M.T., Oliveira, F.L.C. and Ferrer, A.L.C. (2018) Time Series Analysis with Explanatory Variables: A Systematic Literature Review. Environmental Modelling \& Software, 107, 199-209. https://doi.org/10.1016/j.envsoft.2018.06.004

[11] Engle, R.F. and Patton, A.J. (2007) What Good Is a Volatility Model? Forecasting Volatility in the Financial Markets, 47-63. https://doi.org/10.1016/B978-075066942-9.50004-2

[12] Sarkar, K.P., Singh, K.N., Lama, A. and Gurung, B. (2020) Incorporation of Exogenous Variable in Long Memory Model: An ARFIMAX-GARCH Framework.

[13] Hagiwara, M. and Herce, M.A. (1999) Endogenous Exchange Rate Volatility, Trading Volume and Interest Rate Differentials in a Model of Portfolio Selection. Review of International Economics, 7, 202-218. https://doi.org/10.1111/1467-9396.00157

[14] Samiev, S. (2013) GARCH $(1,1)$ with Exogenous Covariate for EUR/SEK Exchange Rate Volatility: On the Effects of Global Volatility Shock on Volatility.

[15] Sharma, J.L., Mougoue, M. and Kamath, R. (1996) Heteroscedasticity in Stock Market Indicator Return Data: Volume versus GARCH Effects. Applied Financial Economics, 6, 337-342. https://doi.org/10.1080/096031096334132

[16] Banerjee, A., Paul, S., Hazra, S. and Dalmia, R. (2011) Impact of Information Arrival on Volatility of Intraday Stock Returns. Technical Report, Working Paper Series: WPS/Indian Institute of Management Calcutta, Calcutta.

[17] Kauffman, K. and Weerapana, A. (2006) The Impact of AIDS-Related News on Exchange Rates in South Africa. Economic Development and Cultural Change, 54, 349-368. https://doi.org/10.1086/497009

[18] Yeasin, Md., Singh, K.N., Lama, A. and Paul, R.K. (2020) Modelling Volatility In- 
fluenced by Exogenous Factors Using an Improved GARCH-X Model. Journal of the Indian Society of Agricultural Statistics, 74, 209-216.

[19] Paul, R.K., Himadri, G., et al. (2014) Development of Out-of-Sample Forecasts Formulae for ARIMAX-GARCH Model and Their Application. Journal of the Indian Society of Agricultural Statistics, 68, 85-92.

[20] Anggraeni, D., Jaghdani, T.J., Adhi, A.K., Rifin, A. and Brummer, B. (2014) Rice Price Volatility Measurement in Indonesia Using GARCH and GARCH-X Method. Conference on International Research on Food Security, Washington DC, September 2014, 29-31.

[21] Engel, C. and West, K.D. (2005) Exchange Rates and Fundamentals. Journal of political Economy, 113, 485-517. https://doi.org/10.1086/429137

[22] Dreger, C. and Kholodilin, K.A., Ulbricht, D. and Fidrmuc, J. (2016) Between the Hammer and the Anvil: The Impact of Economic Sanctions and Oil Prices on Russia's Ruble. Journal of Comparative Economics, 44, 295-308. https://doi.org/10.1016/j.jce.2015.12.010

[23] Blattman, C. and Miguel, E. (2010) Civil War. Journal of Economic Literature, 48, 3-57. https://doi.org/10.1257/jel.48.1.3

[24] Collier, P. and Hoeffler, A. (1998) On Economic Causes of Civil War. Oxford Economic Papers, 50, 563-573. https://doi.org/10.1093/oep/50.4.563

[25] Serneels, P. and Verpoorten, M. (2015) The Impact of Armed Conflict on Economic Performance: Evidence from Rwanda. Journal of Conflict Resolution, 59, 555-592. https://doi.org/10.1177/0022002713515409

[26] Apergis, N. and Rezitis, A.N. (2011) Food Price Volatility and Macroeconomic Factors: Evidence from GARCH and GARCH-X Estimates. Journal of Agricultural and Applied Economics, 43, 95-110. https://doi.org/10.1017/S1074070800004077

[27] Han, H. and Kristensen, D. (2014) Asymptotic Theory for the QMLE in GARCH-X Models with Stationary and Nonstationary Covariates. Journal of Business \& Economic Statistics, 32, 416-429. https://doi.org/10.1080/07350015.2014.897954

[28] Raleigh, C., Linke, A., Hegre, H. and Karlsen, J. (2010) Introducing ACLED: An Armed Conflict Location and Event Dataset: Special Data Feature. Journal of Peace Research, 47, 651-660. https://doi.org/10.1177/0022343310378914 